\title{
Effects of Climate Change on Canadian Forest Fires
}

AUTHORS: Curtis Chong ${ }^{1}$, Emily Huang ${ }^{1}$, Leon Chen ${ }^{1}$

SCHOOL: Pierre Elliott Trudeau High School, Toronto, Canada

\section{Abstract}

This study aimed to determine the effects of climate change on forest fire trends in Canada by measuring correlations between weather conditions, and the frequencies and sizes of forest fires. Upon identifying the correlations, a model was created to understand future forest fire trends in order to prevent the increasing occurrences of forest fires, and to devise solutions to reduce their damages.

The data obtained from the Canadian National Fire Database was modeled with a linear regression to predict and correlate weather conditions with future forest fire trends. It was concluded that temperature and wind speed correlated positively with forest fire frequency and size, while precipitation presented a negative correlation.

To reduce the harmful effects of forest fires, cloud seeding can be used to create more precipitation, and wind farms can be built to lower wind speeds and attract lightning. However, more research and stricter policies directly targeting climate change is a necessity when it comes to decreasing forest fire trends and improving longterm security.

\section{Key Words}

Forest Fire, Climate Change, Canada, Big Data

\section{Introduction}

The 2016 Fort McMurray Fire in Alberta exemplifies the extent of damages caused by forest fires. The incident destroyed 2400 buildings and 1600 private residences, with the total cost of damages estimated by the Conference Board of Canada to be between $\$ 4$ billion and $\$ 9$ billion [1]. The Alberta government also spent $\$ 160$ million on evacuation procedures, disbursing $\$ 1250$ to each adult and $\$ 500$ to each dependent [1]. In addition, the event forced 14 days of lost oil production averaging around 1.2 million barrels per day, equating to around $\$ 985$ million in lost real GDP [1], and allowed contaminants deposited on trees and soils such as mercury, heavy metals, and polycyclic aromatic hydrocarbons to be released into the air, creating a more toxic smoke than that of regular forest fires [2]. In burning the buildings, houses, cars, furniture, etc., the fire further released a wide range of toxins and small particles potentially dangerous for the lungs [2]. Rainfall also caused a toxic surge into the water systems, including the Athabasca River, adding to the aquatic pollution already caused by contaminants from oil sand production [2].

Given its evident harms, preventing the increase of forest fires appears to be an important endeavor. In fact, the Ecological Institute at Northern Arizona University (NAU) found prevention efforts can reduce the cost of rehabilitating an area by $70 \%$, resulting in a cost between $\$ 200$ to $\$ 400$ per hectare [3]. While the differences in region and climate does not allow a direct comparison between Canadian forest fires and those studied at NAU, the consistently heavy burden of forest fire relief on taxpayers demands a re-evaluation of policies surrounding the fires. For the past decade, British Columbia, which experienced around 900 forest fires between April and July 2015 , has overspent their wildfire fighting budget almost every fiscal year [4]. Table 1 depicts these discrepancies between the British Columbia wildfire management budget and spending, evidently as the economic and environmental tolls of forest fires are consistently greater than expected.

In developing a model analyzing climate conditions affecting the fires, our project aims to assist the targeting of government funds for more efficient and long-term productive uses. For instance, through understanding the atmospheric conditions that cause more frequent and intense forest fires, we can implement solutions which directly target those conditions. On a grander scale, in demonstrating the extent to which climate change intensify forest fires, our model may provide further concrete support for the urgent need for stronger policies against overall climate change.

\section{Materials and Methods}

To understand the effects of climate change on forest fire trends, historic fire data from the years 1949 to 2015 were extracted from the Canadian National Fire Database [5]. Each fire incident (provided by a pair of latitudinal and longitudinal coordinates from the database) was matched with the nearest weather station to determine weather conditions at the time of the fire; namely, precipitation, temperature, and wind. The model also considered burn rate, measured from a scale of 1-3, based on different types of trees in the area. A Principal Component Analysis (PCA) was first conducted to 
Table 1: The table depicts the British Columbia wildfire management budget vs. spending per fiscal year (in millions of dollars).

\begin{tabular}{c|c|c|}
\hline Fiscal Year & Budget & Spending \\
\hline $2014 / 15$ & 63 & 297 \\
\hline $2013 / 14$ & 63 & 122 \\
\hline $2012 / 13$ & 62 & 133 \\
\hline $2011 / 12$ & 63 & 53 \\
\hline $2010 / 11$ & 52 & 212 \\
\hline $2009 / 10^{*}$ & 409 & 382 \\
\hline $2008 / 09$ & 56 & 82 \\
\hline $2007 / 08$ & 56 & 98 \\
\hline $2006 / 07$ & 56 & 159 \\
\hline $2005 / 06$ & 55 & 47 \\
\hline $2003 / 04$ & 55 & 371 \\
\hline
\end{tabular}

Table 2: The table outlines the two sets of variables, without and with the success of the Paris Agreement goals, used to predict size of forest fires in 2050 which include average temperature, the month of data, burn rate (Burn_r), and average precipitation (Prec).

\begin{tabular}{|c|c|c|c|c|}
\hline PA & Temp & Month & Burn_R & Prec \\
\hline Not Met & 5.8 & 2 & 1 & 10.3 \\
\hline Met & 4.5 & 2 & 1 & 11.0 \\
\hline
\end{tabular}

determine key features and reduce the dimensionality of the dataset. Then, a linear regression algorithm was applied to the simplified dataset to predict the size of forest burned using atmospheric conditions. Next, this model was used to predict and compare the size of forest fires in 2050 using current projections of atmospheric conditions and those satisfying the Paris Climate Change Agreement goals [6]. The difference between the two shows hectares of forests saved. The number of forest fires at the year 2050 was then multiplied by the average area of forest saved to determine the forest area that would be protected under global climate reform. Additionally, a k-means clustering was used to determine optimal placements of 200 wind farms around Canada and specifically the Northern-Albertan region. These wind farms are to be placed in the centroids of area with previous incidents of forest fires to achieve maximum impact.

\section{Results}

A linear model was used the following sets of variables to predict the size of Hectares burned (Table 2).

The linear regression yielded an R-value of 0.024192099753 , a p-value of 0.082902726074 , and a standard deviation of 2.93742495196 .

The first model projected an annual burn area of around 1300 hectares while the second model projected a burn area of 1600 hectares, yielding a difference of 300 .

Based on the frequency of forest fires in the National Fire Database, the 2050 fire frequency is projected to be 6280 natural wildfires. When multiplied by the amount of hectares saved from the Paris Climate Agreements, 1,921,680 hectares of forest can be saved annually.

\section{Discussion}

The positive correlation between temperature and frequency with the size of forest fires is intuitive, as heat is one element of the combustion triangle. The radiation from the sun heats and dries shrubbery and sticks on the ground to become potential fuels. Warmer temperatures also allow these fuels to ignite more readily and burn faster, increasing the size of forest fires.

The principal components revealed a positive correlation between wind speed and the frequency and size of forest fires, which can be attributed to the role of wind in supplying the fire with fresh oxygen, drying potential fuel, and increasing the rate at which the fire progresses across the terrain. Furthermore, we found a negative correlation between precipitation and the frequency and size of forest fires which demonstrates the role of moisture in lowering the likelihood of forest fires igniting. As water has a very high heat capacity, moisture existing as precipitation and humidity can slow the rate and decrease the intensity of forest fires by absorbing the 


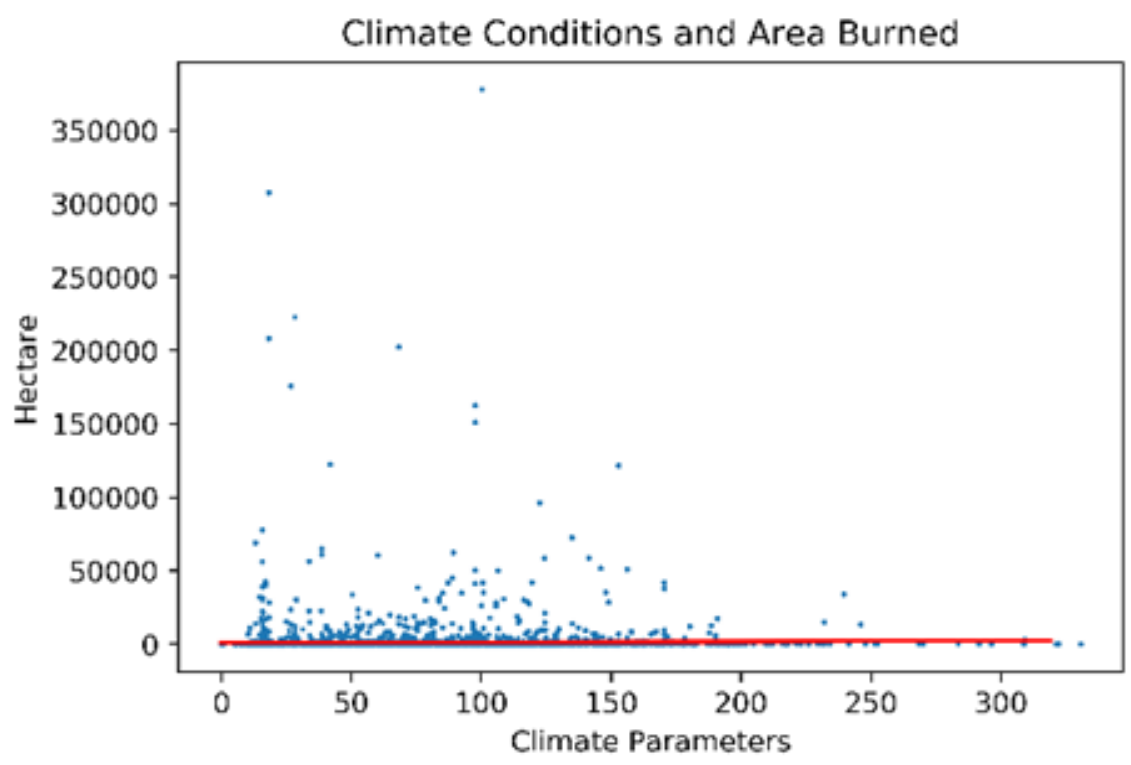

Figure 1: Relationship between principal components and area burned.

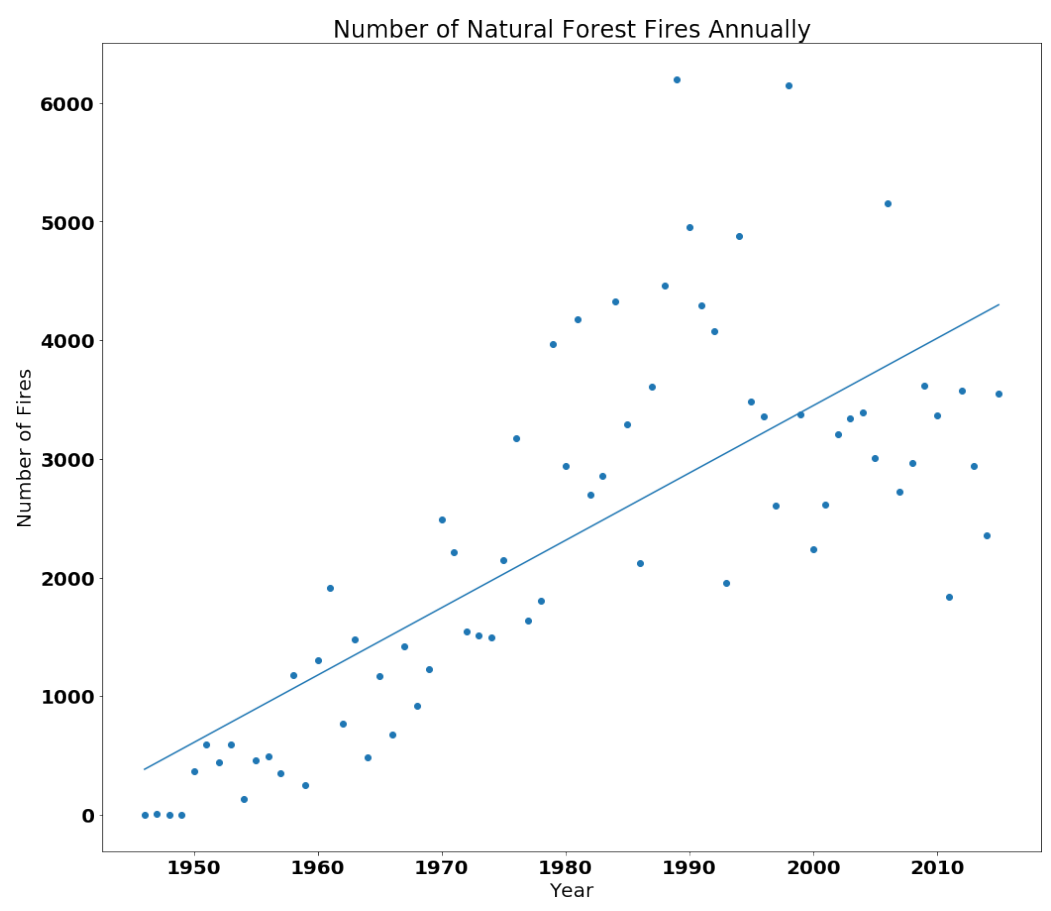

Figure 2: Frequency of forest fires in Canada since 1940.

fire's heat.

As the climate data used for each forest fire was attained from the nearest fire station rather than the direct site of the fire, there may exist discrepancies in weather conditions that slightly distort the result.

It is evident that action is required to prevent potential fires in Canada's forests. To mitigate the effects of climate change, the province of Alberta must diversify its workforce and build wind farms in its northern regions. Such action will direct the province towards clean energy and protect Canada's forests.

As indicated by the study, high wind speeds intensify forest fires by supplying fresh oxygen and tilting the flames forward to dry and preheat surrounding vegetation. Thus, we recommend building wind farms. The wind farms would effectively remove kinetic energy from the air and reduce wind speed in the region (Figure 3).

These wind farms can also attract lightning strikes and reduce the frequency of forest fires incited by lightning, which account for $81 \%$ of the total area burnt [7]. Furthermore, wind farms should 
specifically be built in regions at high risk for forest fires (Figure 4), such as in Northern Alberta instead of primarily in Ontario, as previous wind energy investment trends have indicated [8].

A method frequently employed by other nations including the U.S., China, and Thailand to prevent and put out forest fires is cloud seeding, a weather modification mechanism which shoots seeding agents such as silver iodide or salt into clouds to induce precipitation and add moisture to the environment [9]. Cloud seeding efforts can reduce the strength of forest fires or delay them temporarily, allowing time for creating evacuation and preparation policies to minimize damage. Using the model from this study, we can allocate cloud seeding projects to areas that will benefit most.

\section{Conclusion}

Though our study focuses on the impact of climate change on forest fires, man-made forest fires account for around $43 \%$ of forest fires exceeding four hectares [10]. As many man-made forest fires are caused by ignited exhaust pipes covered by clumps of mud and grass or irresponsible practices by the oil and gas industry, increased awareness of safe practices should be encouraged by municipalities and poor industry practices should be penalized. Such measures will prevent unnecessary forest fires and reduce the negative impacts while other policies are devised to reduce the increasing occurrence and magnitude of forest fires due to climate change.

In addition to the aforementioned measures, climate change is the most significant issue to be addressed. To tackle climate change and meet the goals of the Paris Agreement, we first advocate for reducing and eventually eliminating the $\$ 3.3$ billion fossil fuel subsidies which effectively pay polluters $\$ 19$ for each tonne of carbon dioxide emitted. If the subsidy is not removed, this amount will increase to $\$ 50$ per tonne by 2022 [11]. The government should instead subsidize the research, development, and growth of green energy technologies and businesses. These efforts will also help domestic green energy businesses become more competitive in

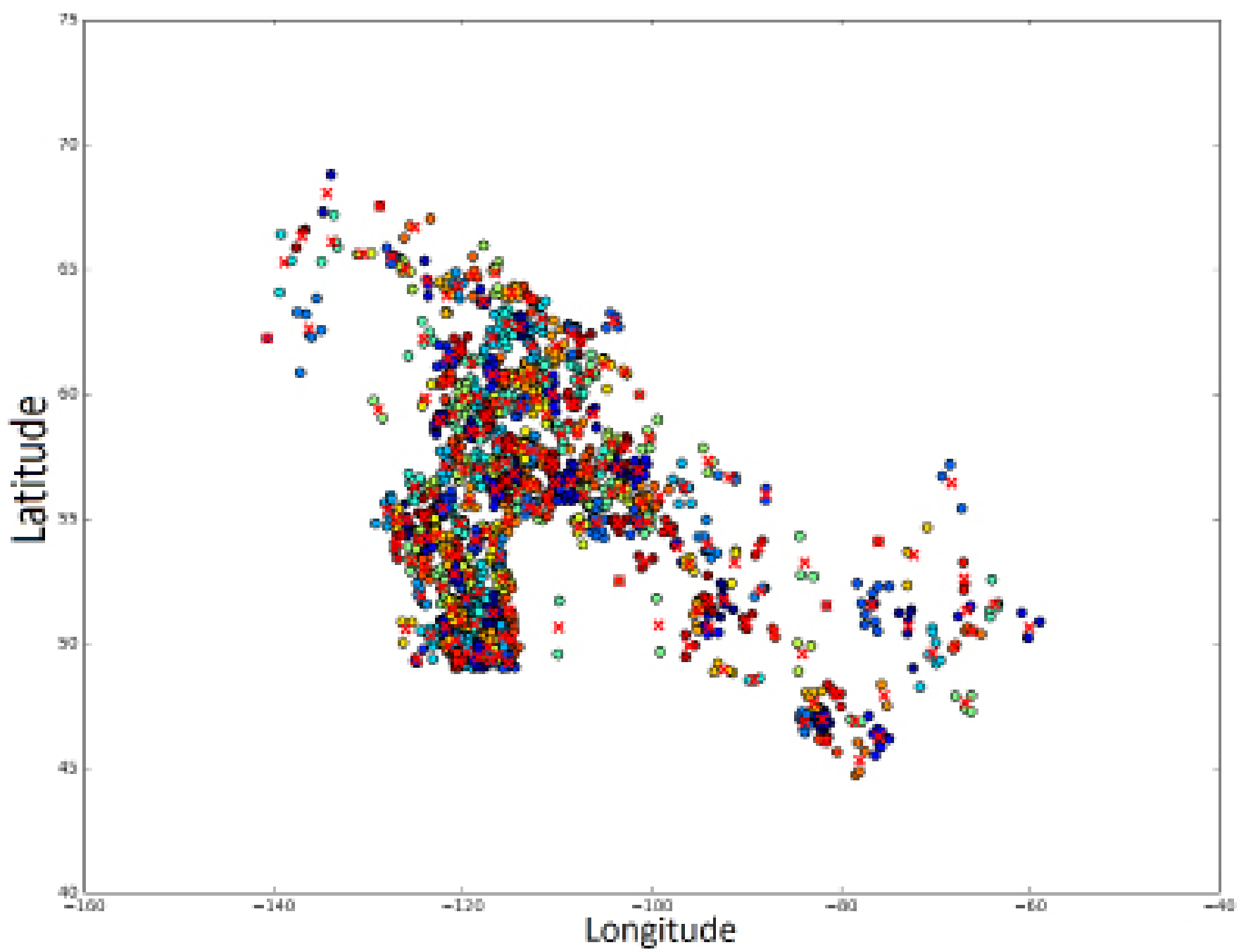

Figure 3: Locations of forest fires (dots) and optimal wind farm locations (x) based on longitude and latitude. 


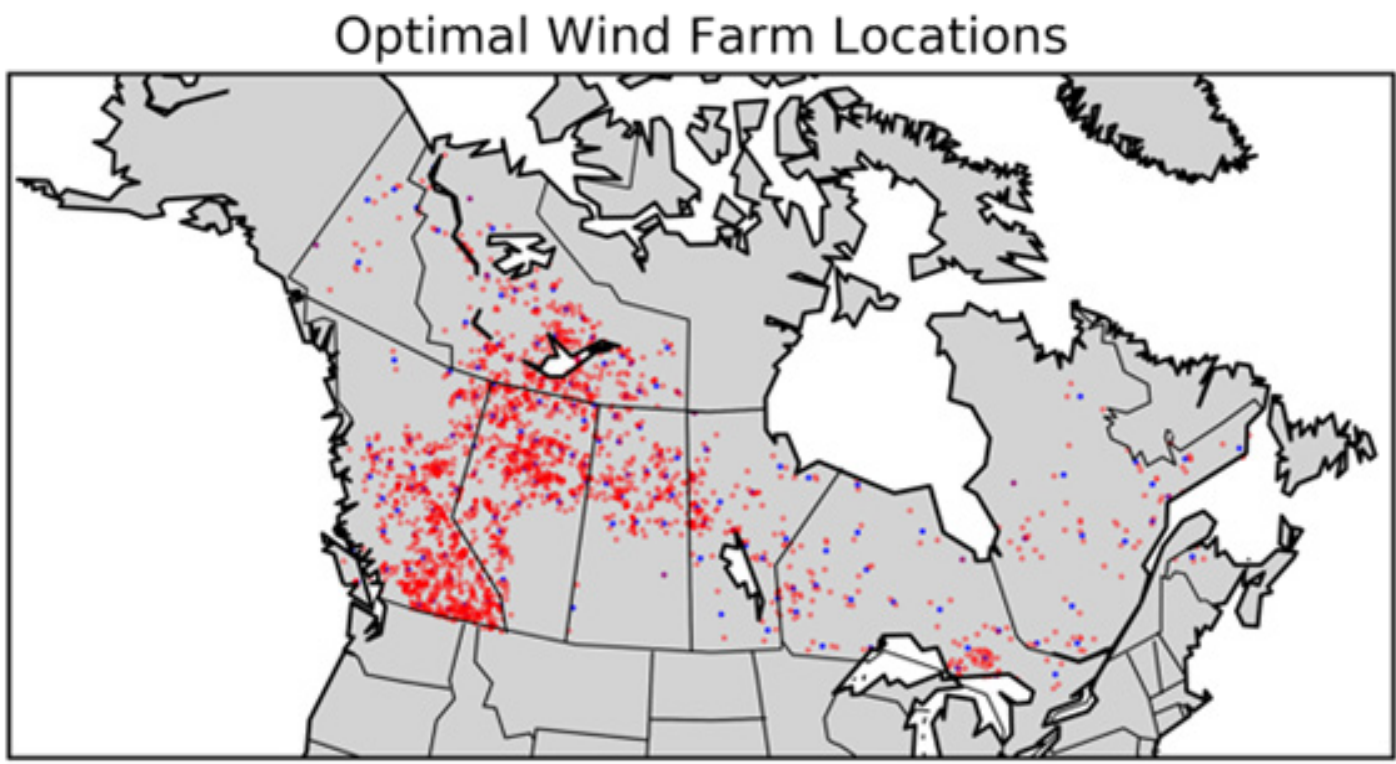

Figure 4: Optimal wind farm (blue) locations with respect to forest fire (red) occurrences.

meeting the growing global need for green energy.

Further models can be built to more precisely predict the intensity and location of imminent forest fires, rather than merely determining the overall trend, to assist in directing prevention and suppression efforts. This model would likely require greater understanding in the scope and depth of the weather conditions that cause and worsen forest fires.in

To more stringently target climate change, further research can be conducted comparing greenhouse gas outputs and the economic contribution of various industries to determine which industries should be phased out or reformed to be more efficient.

\section{References}

[1] Economic Impacts of the Fort McMurray Wildfires [Internet]. Conferenceboard.ca. The Conference Board of Canada. ; 2016 [cited 2017Jan10]. Available from: http://www.conferenceboard.ca/press/newsrelease/16-05-17/economic_impacts_of_th E_fort_mcmurray_wildfires

[2] Leahy S. Canada wildfire - what are the environmental impacts? [Internet]. The Guardian. Guardian News and Media; 2016 [cited 2017Jan10]. Available from: https://www.theguardian.com/environment/2016/may/11/ canada-wildfire-environmental-impacts-fort-mcmurray

[3] Peterson J. Wildfire Prevention Costs Far Less Than Fires (Op-Ed) [Internet]. LiveScience. Purch; 2014 [cited 2017Jan10]. Available from: http:// www.livescience.com/47894-wildfire-prevention-costs-less-than-cleanup. html

[4] Dunn YTT. INTERACTIVE: The cost of B.C. wildfires over the last decade [Internet]. Global News. Global News; 2015 [cited 2017Jan10]. Available from: http://globalnews.ca/news/2101720/interactive-the-cost-ofb-c-wildfires-over-the-last-decade

[5] Natural Resources Canada [Internet]. Canadian Wildland Fire Information System; 2016 Jun 21 [cited 2017 Jan 10]. Available from http://cwfis. cfs.nrcan.gc.ca/datamart

[6] Canadian Climate Data and Scenarios [Internet]. Introduction to

\section{Acknowledgements}

First, we want to thank our mentor Ching Pan for finalizing our plan. We also want to thank the Canadian National Fire Database for providing us with the data set and Environment Canada for compiling the historic weather data. Lastly, we thank Dr. Sacha Noukhovitch for the ongoing support.

TAR/AR4 scenarios; Available from http://climate-scenarios.canada. $\mathrm{ca} /$ ?page $=$ main

[7] Environment and Climate Change Canada [Internet]. Lightning and forest fires; 2016 Jun 21 [cited 2017 Jan 10]. Available from https://www. ec.gc.ca/foudre-lightning/default.asp?lang $=E n \& n=48337 E A E-1$

[8] Installed Capacity [Internet]. Canadian Wind Energy Association. Canadian Wind Energy Association; 2016 [cited 2017Jan10]. Available from: http://canwea.ca/wind-energy/installed-capacity

[9] Vanderklipe N. Could cloud seeding have saved Fort McMurray? Does it even work? [Internet]. The Globe and Mail. The Globe and Mail; 2016 [cited 2017Jan10]. Available from: http://www.theglobeandmail.com/news/ alberta/could-cloud-seeding-have-save-fortmcmurray/article29957745

[10] Markusoff J. What's to blame for Western Canada's forest fire outbreak? [Internet]. Macleans.ca. Maclean's; 2015 [cited 2017Jan10]. Available from: http://www.macleans.ca/news/canada/whats-behind-westerncanadas-forest-fire-outbreak

[11] Milman O. Canada gives $\$ 3$.3bn subsidies to fossil fuel producers despite climate pledge [Internet]. The Guardian. Guardian News and Media; 2016 [cited 2017Jan10]. Available from: https://www.theguardian.com/ world/2016/nov/15/climate-change-canada-fossil-fuel-subsidies-carbontrudeau 


\section{REVIEW}

\section{by Dr. Bruno C. Mundim}

\section{SciNet}

The authors studied the correlation between weather conditions and forest fire frequency and size. Based on these correlations, they have also built a model to predict the occurrence and severity of these forest fires and used this model to devise solutions to minimize their negative impact.

This is an impressively well written manuscript where the ideas were logically presented with a good command of the language. Probably the most important task a data scientist confronts on her day-to-day activities is asking insightful questions. The authors have just demonstrated that when they went beyond the linear regression technique to build a predictive model using modern statistical learning techniques and to propose solutions based on this model. I would truly like to congratulate the authors on this impressive achievement.

Besides minor text edits I suggested to the authors, a few issues could be worked out to either marginally improve this manuscript or as a starting topic for a more in deep follow-up project. The first issue concerns the use of the "climate change" term without really mentioning if they had actually used the standard averaging over 30 years for weather conditions. It seems to me the correlation studied in this manuscript was related to weather only and not climate. It would be tremendously beneficial to clarify this issue as well as to point out the consequences of climate change to weather events and their subsequent impact on forest fires.

The second issue regards the usage of cloud seeding and wind farms to increase precipitation and to lower wind speeds and attract lightning, respectively. The authors propose them as possible solutions but did not investigate how impactful these ideas actually are. For example, what is the cost of cloud seeding? Is it economically feasible? Is there any study of how much wind speed is reduced by a large wind farm? How large would this wind farm area have to be? What about its shape? What would be the most effective shape? How effective is this farm on attracting lightning? The answers to these questions are fundamentally important to public policing to address the forest fire economic impact. While some of these questions the authors might have already a reasonable answer to be included in this manuscript, others could serve as suggestions for later investigations.

I would like to end this review by congratulating the authors once again on their impressive work and wishing them all the best on their future scientific endeavours. 